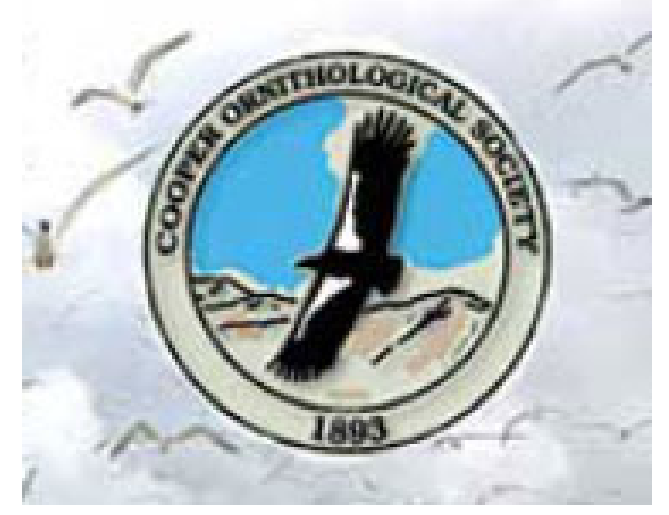

Frequency, Timing and Costs of Intraspecific Nest Parasitism in the Common Eider Author(s): Gregory J. Robertson, Michelle D. Watson, Fred Cooke

Reviewed work(s):

Source: The Condor, Vol. 94, No. 4 (Nov., 1992), pp. 871-879

Published by: University of California Press on behalf of the Cooper Ornithological Society

Stable URL: http://www.jstor.org/stable/1369284

Accessed: $24 / 04 / 201200: 21$

Your use of the JSTOR archive indicates your acceptance of the Terms \& Conditions of Use, available at http://www.jstor.org/page/info/about/policies/terms.jsp

JSTOR is a not-for-profit service that helps scholars, researchers, and students discover, use, and build upon a wide range of content in a trusted digital archive. We use information technology and tools to increase productivity and facilitate new forms of scholarship. For more information about JSTOR, please contact support@jstor.org. 


\title{
FREQUENCY, TIMING AND COSTS OF INTRASPECIFIC NEST PARASITISM IN THE COMMON EIDER ${ }^{1}$
}

\author{
Gregory J. Robertson, Michelle D. Watson and Fred CoOke \\ Department of Biology, Queen's University, Kingston, Ontario K7L 3N6, Canada
}

\begin{abstract}
Intraspecific nest parasitism was studied in the Hudson Bay race of the Common Eider (Somateria mollissima sedentaria), near Churchill, Manitoba $\left(58^{\circ} 24^{\prime} \mathrm{N}, 94^{\circ} 24^{\prime} \mathrm{W}\right.$ ). Nest parasitism was detected by three methods: (1) multiple eggs laid in the same nest on a single day, (2) eggs laid before or after the host's clutch was laid, and (3) large withinclutch variances in egg size and color. It was determined that $42.4 \%(n=153)$ of completed clutches were parasitized. Parasitic eggs were laid significantly earlier in the host's laying sequence than expected by chance: $65 \%$ of parasitic eggs were laid on the first two days of laying. Number of parasitic eggs laid, as a proportion of all eggs, did not change significantly throughout the laying period. The probability of parasitic and host eggs hatching was not significantly different from that in unparasitized nests. Hosts did not reduce their clutch size in response to parasitism, when data were controlled for initiation date, nor did they hatch any fewer of their own young for a given clutch size than unparasitized nests. Parasitized nests were found in areas with higher densities (number of neighbors within $10 \mathrm{~m}$ ) at initiation. Parasitism in this species does not appear to be a salvage strategy and may be part of a mixed or conditional strategy.
\end{abstract}

Key words: Common Eider; Somateria mollissima; intraspecific nest parasitism; hatching success; nesting density.

\section{INTRODUCTION}

Alternative reproductive strategies have received considerable attention in recent years, mostly due to the introduction of a theoretical framework suitable for analyzing these behaviors (Dawkins 1980, Maynard Smith 1982). In general, male alternative reproductive strategies have received more attention (Wells 1977, Cade 1980, Westneat et al. 1990), but female alternative behavioral strategies are just as interesting in an evolutionary sense (e.g., Brockmann et al. 1979). A relatively common alternative strategy available to female birds is intraspecific nest parasitism (Yom-Tov 1980). Intraspecific nest parasitism, when one (or more) female lays eggs in the nest of a conspecific and subsequently does not provide any further parental care, has been found in 1-2\% of bird species (MacWhirter 1989). Precocial species display this behavior more often than altricial species (Yom-Tov 1980, Rohwer and Freeman 1989). Altricial birds are probably limited in the number of offspring they can rear by the number of pre-fledging young they can feed (Lack 1954, Rohwer and Freeman 1989), so there will exist a strong selective pressure to avoid being parasitized. In contrast, the cost of

\footnotetext{
I Received 24 March 1992. Accepted 24 June 1992.
}

raising extra young in precocial birds is not as high (Andersson 1984), if it exists at all (Eadie and Lumsden 1985, but see Amat 1987). Furthermore, Andersson (1984) suggested that since female Anatids are generally philopatric to the breeding site then parasitic females may be related to the host. Thus, the hosts could increase their inclusive fitness by raising related parasitic young. Another possible gain for precocial hosts is the use of non-kin as predator shields (the selfish herd effect; Hamilton 1971).

Despite these suggestions nest parasitism is usually assumed to be costly to the host. Some studies have shown reduced hatchability of host eggs due to nest abandonment or inefficient incubation (Semel et al. 1988; Lank et al. 1990; Sorenson, in press) although other studies have failed to show a cost to the host's young (Young and Titman 1988, Eadie 1989). If such costs to the host do exist then mechanisms should have evolved to prevent parasitism. These mechanisms have been described in some altricial species (Emlen and Wrege 1986, Moller 1987). Andersson and Eriksson (1982) similarly showed that Goldeneyes (Bucephala clangula) reduce their clutch size in response to artificial parasitism but only when parasitism occurs early in the females laying cycle. However, Andersson and Eriksson's results were questioned by Rohwer 
(1985) and this has not been seen in Wood Ducks (Aix sponsa; Clawson et al. 1979, Huesmann et al. 1980) or other species (Rohwer 1984). In contrast, parasitic eggs have been shown to have a reduced hatchability, mainly due to the improper timing of laying with respect to the host's onset of incubation (Eadie 1989; Sorenson, in press).

An aspect of intraspecific nest parasitism that has received considerable attention is its occurrence in colonial birds. It has been suggested that parasitism rates should be high in colonial birds because it will be easier to find potential hosts (Andersson 1984). Among the colonial, altricial birds most work has been done with Cliff and Barn Swallows (Hirundo pyrrhonta and H. rustica). Brown (1984) and Moller (1987) both found that parasitism rates increased with colony size in swallows, up to a certain level. Similar patterns have been found in the Anatidae. Eadie (1989) showed that parasitism rates were higher in Goldeneyes around lakes with more nesting pairs on them and included a density-dependent effect in his model of the evolution of this behavior. Parasitized Gadwall (Anas strepera) nests were also found in areas of higher density (Hines and Mitchell 1984).

The Hudson Bay race of the Common Eider is ideally suited for a study of intraspecific nest parasitism. It nests colonially in high but varying densities, allowing large samples to be collected and comparisons to be made between different nesting densities. Although the Common Eider is a well studied species (e.g., Milne 1974; Munro and Bedard 1977a, 1977b; Swennen 1989), and intraspecific nest parasitism was first recorded over fifty years ago (Robertson 1929), nest parasitism has not been studied in detail. The specific aims of this study are: (1) to develop a method to identify parasitic eggs in the field and to describe the frequency and timing of parasitism, (2) to determine the hatchability of parasitic eggs, and eggs in parasitized (hosts) nests compared to unparasitized nests, and (3) to investigate if nesting density mediates parasitism rates in this colonial species.

\section{STUDY AREA AND METHODS}

Field work was carried out between April and August 1991, at the Queen's University Tundra Biology Station located in the Mast River delta at La Pérouse Bay, Manitoba $\left(58^{\circ} 24^{\prime} \mathrm{N}, 94^{\circ} 24^{\prime} \mathrm{W}\right)$. A large colony of Common Eiders is located on the fresh water islands of the Mast River delta.
Schmutz et al. (1983) describes the study site. In the present study, the two areas referred to as "Eider Islands" ( $n=75$ nests $)$ and "Delta" $(n=$ 204 nests) were monitored through the nesting period (see Fig. 1 in Schmutz et al. 1983). Each area was searched at least daily for new nests and previously found nests were revisited. When a new egg was found the time was recorded, the egg was numbered with a felt marker, the length and maximum breadth of the egg was measured with a vernier calliper (to $\pm 0.1 \mathrm{~mm}$ ) and the egg was weighed with a $300 \mathrm{~g}$ spring pesola (to \pm 1 g). The color of an egg was assigned by visually matching the egg to a set of paint color cards. The contents of the nests were noted on each subsequent visit. All new nests were marked with small nest markers placed $30 \mathrm{~cm}$ from the nest cup. Once a female had been incubating for two days the nest was not visited again until hatch. During hatch, nests were visited every 1-2 days and the number of eggs, egg membranes and young were recorded. Ducklings were considered to have hatched successfully and left the nest if they were seen as completely dried and active in the nest or if an egg membrane could be attributed to the egg in the nest (Girard 1939). Nests were mapped and inter-nest distances were recorded after hatch, either using large scale aerial photographs when distances were large, or a surveyor's tape $( \pm 10 \mathrm{~cm})$ for nests closer than $20 \mathrm{~m}$ apart.

Parasitic eggs could be identified on the basis of anomalous laying patterns. Female Common Eiders lay approximately every $27 \mathrm{hr}$ (M. D. Watson, unpubl. data), therefore those nests that received more than two eggs within $27 \mathrm{hr}$ must contain parasitic eggs. These nests will be referred to as multiple egg per day nests. This method identified parasitized nests but not the individual parasitic eggs; egg length, breadth and color were used to identify the parasitic eggs themselves. Colors were assigned an integer value on a linear scale with brown and blue-green at the two extremes and mixtures of these two colors in the middle. Length and breadth varied in a consistent manner over the laying sequence (Robertson and Cooke, unpubl. manuscript). To reduce the within-clutch variation caused by this effect the length and breadth of each egg was subtracted from the population mean for an egg of a given sequence. All three measures (length, breadth and color) were standardized to means of 0 and standard deviations of 1 . Within-clutch 
TABLE 1. Differences in the within-clutch variance of the three egg characteristics (length, breadth and color) between single and multiple egg per day clutches. See text for details of the standardization of these variables. Values are means $\pm 1 \mathrm{SD}$.

\begin{tabular}{|c|c|c|c|c|c|}
\hline \multirow[b]{2}{*}{ Egg character } & \multicolumn{2}{|c|}{ Mean within-clutch variance } & \multirow[b]{2}{*}{$F$} & \multirow[b]{2}{*}{ df } & \multirow[b]{2}{*}{$P$} \\
\hline & Multiple eggs & Single eggs & & & \\
\hline Length & $0.80 \pm 1.35$ & $0.65 \pm 1.70$ & 0.46 & 1,236 & 0.498 \\
\hline Breadth & $0.77 \pm 1.19$ & $0.53 \pm 0.71$ & 3.98 & 1,236 & 0.047 \\
\hline Color & $0.72 \pm 0.66$ & $0.43 \pm 0.52$ & 12.79 & 1,205 & $<0.001$ \\
\hline
\end{tabular}

variances of these three measures were calculated for single egg per day and multiple egg per day nests (Table 1). This suggested that multiple egg per day nests contained parasitic eggs. Presumably, the parasitic egg caused the variance in the clutch to be higher than a unparasitized clutch. Eggs that were laid on the same day were then compared to the rest of the clutch. The egg that caused the largest increase in variance was classified as the parasitic egg. An additional method was used to detect eggs that were laid in sequence with the host's clutch (i.e., eggs laid the day before or the day after the host's clutch). All clutches were examined to see if they had unusually large variances (greater than two standard deviations) in length, breadth, and color caused by the first or last egg. If an odd first egg was detected it was excluded from the host's clutch and not considered parasitic, whereas odd last eggs were considered parasitic. Eggs laid more than $24 \mathrm{hr}$ before the host's clutch (14 cases) were also excluded from the analysis.

If multiple eggs were found on the first day the nest was initiated the nest received a further analysis. A within-clutch, cluster analysis using length, breadth and color as the variables was performed on these nests. Since the cluster analysis was performed independently of whether the egg was laid singly or with other eggs on the same day, it provides an independent measure of deviant eggs. This was necessary because multiple eggs on the first day could simply be a result of the nests not being found on the first day the host initiated. However, some nests in the "Delta" area were visited more than once a day as part of another study. If multiple eggs were found on the first day in these nests, it was possible to identify whether the putative parasitic egg was laid before or after the host began her clutch.

Sample sizes vary depending on the analysis as only those nests with the complete relevant information were included. Completed clutches (no new eggs for two days) for which the exact date of initiation was known was the smallest but most comprehensive data set $(n=153)$. The restrictions on each analysis are presented in the text and tables. Statistical tests and data manipulations were done using the SAS (SAS Institute $1985)$ package. $P$ values less than 0.05 were considered significant. All tests were two-tailed.

\section{RESULTS}

\section{FREQUENCY OF PARASITISM}

Of the 153 complete clutches, 60 (42.4\%) contained one or more parasitic eggs. When incomplete clutches are included, 65 of 236 (27.5\%) nests were parasitized (incomplete clutches were either abandoned or depredated, mainly by foxes or gulls, prior to clutch completion). In the 65 parasitized clutches, $44(67.7 \%)$ contained one parasitic egg, $18(27.6 \%)$ contained two parasitic eggs, and three contained three (4.7\%) parasitic eggs. In all, 89 of 957 (9.2\%) of eggs laid were identified as parasitic. Of these eggs $85(95.5 \%)$ were laid on the same day as the host laid an egg and were detected by the multiple eggs in one day method. The other four (4.5\%) were laid after the host's clutch and were detected because they increased the within-clutch variance in morphology and color greatly (by more than two standard deviations). Of this total of 89 eggs, there were 18 that may not have been parasitic: four eggs were detected because of their large deviation from the rest of the clutch, six eggs were laid on the first day of initiation but not identified as the most deviant egg by the cluster analysis, and eight were eggs known to be laid first on the same day as the host initiated. If these eggs were excluded this would provide a minimum parasitism rate of $30.0 \%$ (46 of 153 ) of all nests.

\section{TIMING OF PARASITISM}

Parasites laid their eggs early in the laying cycle of their host (Fig. 1). A large proportion (greater 


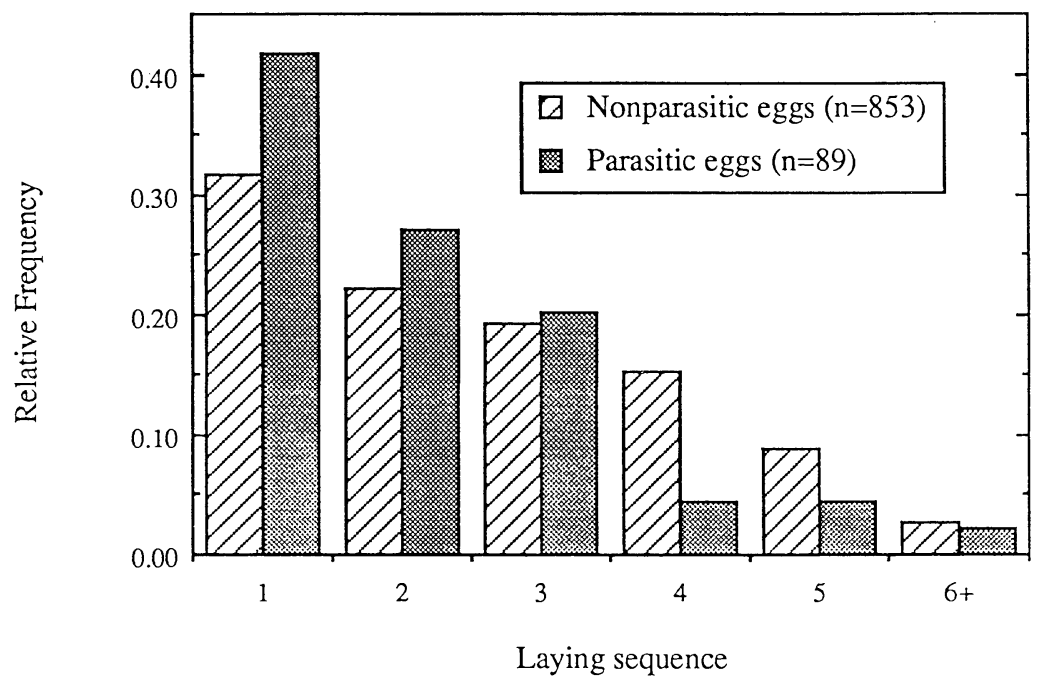

FIGURE 1. Timing of laying of parasitic eggs with respect to the host female's laying sequence in contrast to the frequency of non-parasitically laid eggs. The two distributions are significantly different (log-likelihood ratio test, $G=13.87$, $\mathrm{df}=5, P=0.016)$.

than $65 \%$ ) of the parasitic eggs were laid on the first two days of laying. The cluster analysis for nests with multiple eggs on the first day showed that in 33 of $39(85 \%)$ cases the most different egg was the previously identified parasitic egg. For those nests where visits were made more than once per day, in 8 of 13 cases the probable parasitic egg was laid first. Overall, there was no difference in the occurrence of parasitic eggs and normal eggs over the initiation period (Fig. 2,
Kolmogorov-Smirnov test for continuous data, $\mathrm{D}_{\max }=0.0854, P>0.50$ ).

\section{SUCCESS OF PARASITES AND HOSTS}

Clutch size. The mean clutch size for incubating nests, with known parasitic eggs excluded, was $4.42 \pm 1.17(n=153)$. There was a significant decline in clutch size over the initiation period (Pearson's correlation coefficient, $r=-0.24, \mathrm{P}$ $=0.003, n=153)$. The clutch size of host and

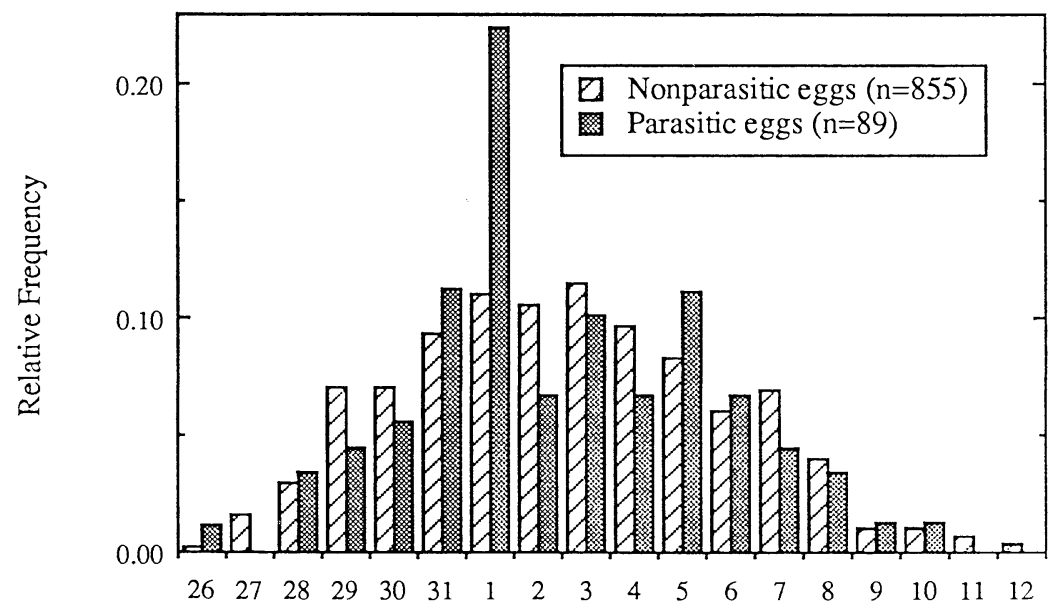

Date (May 26 - June 12, 1991)

FIGURE 2. Timing of laying of parasitic and non-parasitic eggs over the whole initiation period. 
TABLE 2. Clutch sizes for host (parasitic eggs excluded) and unparasitized females, for nests initiated early, in the middle and late in the laying period, and for all nests.

\begin{tabular}{|c|c|c|c|c|c|c|}
\hline \multirow[b]{3}{*}{ Initiation date } & \multicolumn{4}{|c|}{ Clutch size } & \multirow[b]{3}{*}{$t$} & \multirow[b]{3}{*}{$P$} \\
\hline & \multicolumn{2}{|c|}{ Unparasitized females } & \multicolumn{2}{|c|}{ Host females } & & \\
\hline & Mean \pm SD & $n$ & Mean \pm SD & $n$ & & \\
\hline Early nests ( $<31$ May) & $4.90 \pm 1.27$ & 39 & $4.50 \pm 1.37$ & 16 & 1.03 & 0.31 \\
\hline Middle nests ( 31 May-3 June) & $4.32 \pm 0.80$ & 22 & $4.24 \pm 1.05$ & 25 & 0.29 & 0.77 \\
\hline Late nests ( $>3$ June) & $4.21 \pm 1.11$ & 29 & $4.05 \pm 1.15$ & 22 & 0.51 & 0.61 \\
\hline All nests & $4.53 \pm 1.15$ & 90 & $4.24 \pm 1.16$ & 63 & 1.69 & 0.12 \\
\hline
\end{tabular}

unparasitized nests did not differ significantly (Table 2). This trend held when the initiation period was divided into early, mid- and late nesters. There was no effect on clutch size if the nest was parasitized by none, one, or two or more eggs (Analysis of Variance, ANOVA; $F=0.12$, $P=0.89$, df $=2,149$ ). There was also no difference in the clutch size of parasitized nests with respect to when the parasitic egg was laid in the host's laying sequence (ANOVA, $F=1.33, P=$ $0.27, \mathrm{df}=4,57$ ).

Number of ducklings leaving nests and hatchability. There was no significant difference in the mean number of ducklings hatching and leaving the nest of unparasitized and parasitized females (considering the host's females own young only, $P>0.15$, Table 3). Similarly, there was no difference in the number of the host female's own ducklings leaving the nest, regardless of the number of parasitic eggs in the nest (ANOVA, $F=$ $0.22, P=0.61, \mathrm{df}=2,183)$. Similarly, there was no significant difference (log-likelihood ratio test, $G=3.03, \mathrm{df}=2, P=0.22)$ in hatching success of parasitic eggs $(46 \%, n=69)$, host eggs $(48 \%$, $n=267)$ and eggs in unparasitized nests $(42 \%$, $n=575$ ). This included abandoned eggs and those predated during laying, to include all possible fates.

\section{EFFECTS OF NESTING DENSITY}

Nesting density had a significant effect on the level of parasitism (Table 4). All measures of density used showed that higher parasitism rates occurred in areas of higher nest density, but only for the number of neighbors within $10 \mathrm{~m}$ at the time of initiation was this difference significant.

\section{DISCUSSION}

The rate of intraspecific nest parasitism reported in Common Eiders in this study (42.4\%) is relatively high compared to that previously recorded in other species. Most parasitic eggs were de- tected by finding more than one egg per day in a nest. This method (short of direct observation) is probably the most reliable field method of detecting parasitic eggs. The increased variance of egg morphology and color in clutches with multiple eggs per day also support this method. If anything, we are underestimating the parasitism rate by failing to detect eggs laid the day before or after the host's clutch. Frederick and Shields (1986) give an equation to correct for the underestimation of nest parasitism by daily visits. We did not use this equation because we attempted to detect these eggs by looking at clutches with large variances in morphology and color. Of the 24 species of waterfowl reviewed by Rohwer and Freeman (1989), only four species had higher parasitism rates than we report for Common Eider (see also Lokemoen 1991). Two of these species show a marked range of values with average rates of $29.8 \%$ for the Wood Duck (Semel et al. 1988) and 22\% for the Lesser Snow Goose (Lank et al. 1989). Thus, only two species, the Black-bellied Whistling Duck (Dendrocygna autumnalis) and the Red-crested Pochard (Netta rufina) have previously been reported as having higher parasitism rates than the Common Eider.

TABLE 3. Number of ducklings leaving the nests of unparasitized and host (parasitized) females for different clutch sizes, and for all clutches.

\begin{tabular}{|c|c|c|c|c|}
\hline \multirow{3}{*}{$\begin{array}{l}\text { Clutch } \\
\text { size }\end{array}$} & \multicolumn{4}{|c|}{ Number of ducklings leaving the nest } \\
\hline & \multicolumn{2}{|c|}{ Unparasitized females } & \multicolumn{2}{|c|}{ Host females } \\
\hline & Mean \pm SD & $n$ & Mean \pm SD & $n$ \\
\hline 2 & $0.21 \pm 0.63$ & 19 & $1.00-$ & 1 \\
\hline 3 & $1.15 \pm 1.39$ & 20 & $1.73 \pm 1.42$ & 11 \\
\hline 4 & $2.17 \pm 1.76$ & 36 & $1.68 \pm 1.61$ & 22 \\
\hline 5 & $2.91 \pm 2.07$ & 46 & $2.00 \pm 1.83$ & 11 \\
\hline 6 & $3.00 \pm 2.45$ & 6 & $3.66 \pm 1.97$ & 6 \\
\hline 7 & $3.00 \pm 2.64$ & 3 & $3.33 \pm 3.05$ & 3 \\
\hline 8 & $3.00 \pm 4.36$ & 3 & - & \\
\hline Total & $2.05 \pm 2.05$ & 133 & $2.06 \pm 1.80$ & 54 \\
\hline
\end{tabular}


TABLE 4. Nearest neighbor distances and nest densities for parasitized and unparasitized nests. Values are means $\pm \mathrm{SD}$.

\begin{tabular}{lccccc}
\hline \hline \multicolumn{1}{c}{ Density measure } & Parasitized nests & Unparasitized nests & $n$ & $t$ & $P$ \\
\hline Nearest neighbor $(m)$ (using all nests) & $1.91 \pm 1.55$ & $1.47 \pm 1.56$ & 152 & 1.87 & 0.063 \\
Nearest neighbor at start of laying $(\mathrm{m})$ & $2.55 \pm 1.91$ & $2.02 \pm 1.98$ & 123 & 1.47 & 0.143 \\
No. of neighbors within 10 m & $7.24 \pm 7.26$ & $5.41 \pm 6.86$ & 245 & 1.84 & 0.067 \\
No. within 10 m at start of laying & $3.73 \pm 4.82$ & $2.29 \pm 3.65$ & 245 & 2.31 & 0.023 \\
\hline
\end{tabular}

Even our minimum estimate of nest parasitism $(30.0 \%)$ is relatively high compared to studies on a wide range of other species (Rohwer and Freeman 1989, Lokemoen 1991).

Eadie et al. (1988) reviewed several hypotheses which explain why intraspecific nest parasitism exists at all. These hypotheses were: (1) reproductive error, (2) inadvertent competition for nest sites, (3) the salvage hypotheses, and (4) parasitism as part of a mixed evolutionarily stable strategy (ESS). All of these hypotheses make predictions which can be tested with our data. The early laying of parasitic eggs with respect to the host's laying sequence reported in the present study suggest a number of hypotheses, in particular that parasitism is a well-developed strategy in this population. Female Common Eiders begin to attend their nests on about day three or four after clutch initiation (G. J. Robertson, pers. observ.). If Eider females defend their nests against parasitism, as occurs in many other species (Emlen and Wrege 1986, Moller 1987, Lank et al. 1989), then parasitism would be easiest before the female begins to attend the nest. The higher than expected proportion of parasitic eggs laid on day 1 and 2 of the host's laying cycle supports this hypothesis. However, there are other possible explanations for this result. The existence of eggs in a nest that were laid before the attending female began her clutch suggests the possibility that other mechanisms are involved. Two females could begin to initiate in the same nest site with, subsequently, only one female continuing to lay, incubate and raise the brood (Eadie et al. 1988, although parasitic females could be anticipating that another female will eventually use that nest site). The following hypothesis is conceivable for the Common Eider: if simultaneous nest initiation occurred one would expect there to be eggs laid "parasitically" until one of the females began to attend the nest. Whether one female is evicted from the nest site or whether one female abandons her eggs before the inevitable encounter is unknown. The pres- ence of eggs in a nest before the host begins her own clutch support the "inadvertent nest site competition hypothesis" (Eadie et al. 1988). Indeed, the female who initiates first in a nest could be evicted by a second female (e.g., Erskine 1990). This type of nest site takeover could arise if highquality nest sites are limited and the costs of accepting parasitic eggs is not high. Alternatively, since clutches of one and two eggs were found abandoned in the area (G. J. Robertson, pers. observ.), some females could simply be taking over these abandoned eggs. It is quite possible that all of these scenarios are taking place with different individuals adopting different strategies. However, only some of the parasitic eggs can be explained by the nest takeover hypothesis. At least 71 of 957 eggs (30.0\% of nests) laid in the population were "truly" parasitic.

Parasitic eggs had the same probability of hatching as eggs laid by the Common Eider host female who incubates her own eggs. This is probably the result of the early laying of the parasitic eggs with respect to the host's clutch. Studies in other species have shown that parasitic eggs are no less viable than any other eggs provided they are laid before the host begins incubation. The reduced hatchability of parasitic Lesser Snow Goose eggs was due to the inability of the parasite to lay her eggs before the host began incubation (Lank et al. 1990). Similarly, in the Redhead (Weller 1959) over half of all parasitic eggs were laid after the host female initiated incubation and all of these failed to hatch. Evans (1988) showed that parasitic European Starling (Sturnus vulgaris) eggs laid during the host's laying period had a higher fledging success than those parasitic eggs that were laid after the host had finished laying her clutch. Although Eadie (1989) showed that parasitic Goldeneyes had equal reproductive success to other nesting females this was due to parasites laying, on average, two more eggs than nesting birds and so compensating for the reduced hatchability of their parasitic eggs.

Most parasitic eggs were laid during the peak 
initiation period in Common Eiders. Eider females in poor condition and young birds generally lay later in the initiation period (Spurr and Milne 1976). Since there is no trend for parasitic eggs to be laid late in the initiation period, there is no evidence that immature birds, birds in poor condition, or birds that previously failed are salvaging some reproductive effort (Eadie et al. 1988, salvage hypothesis). It appears that parasitism is a viable means of reproduction in this population and may be part of a mixed ESS, depending, of course, on how many eggs a parasite lays or if parasites themselves nest. Both Goldeneyes and Wood Ducks have been recorded laying parasitically and then laying in their own nest in the same season (Semel and Sherman 1986, Eadie 1989).

In Common Eiders nest density on the day of initiation mediates parasitism rates. We interpret nest density on initiation day as an index of activity around the nesting area. Rohwer and Freeman (1989) predicted that parasitism rates would increase when high densities occur in species with natural variations in nest clumping. Our data support this prediction and suggest it is the activity of nesting females in the area close to a nest that attracts parasites. Other workers have found higher parasitism rates in higher density areas (e.g., Giroux 1981, Hines and Mitchell 1984, Eadie 1989). Brown (1984) showed that increased parasitism in larger colonies was a cost of colonial living and Wood Ducks have been shown to avoid their nest boxes if conspecifics are in the area, because parasitic females cue in on the laying female (Semel and Sherman 1986). Andersson and Eriksson (1982) observed the same phenomenon in Goldeneyes and Lank et al. (1989) observed parasitism events in Lesser Snow Geese only when a female was attending the potential parasitized nest. It appears that parasitic Common Eiders also cue in on active females to find potential hosts. No host costs could be detected at any nesting density in this study even though densities reached very high levels (nearest neighbor distances of less than one meter) compared to those in other Anatidae. So unlike other species, where increased nesting density increased parasitism rates to deleterious levels (e.g., Semel et al. 1988) Common Eiders do not "overparasitize" even when densities are very high.

The high parasitism rate at the one and two egg stage of the host's laying cycle, with onset of incubation not occurring until the three or four egg stage, suggests a possible mechanism for parasitism in the Common Eider. Instead of parasitising occupied nest sites, as occurs in the Lesser Snow Goose (Lank et al. 1989), Eiders may only parasitize unattended nest sites. This will serve to ensure that parasitic eggs will hatch synchronously with the host's clutch and that only one or two parasitic eggs are laid in any one nest. Whether a parasitic female cannot (due to host defense), or selects not to, parasitize attended nests remains unclear.

Although there was no reduction in the host's clutch size or in the number of the host's own young leaving the nest, there may still be costs to being parasitized. Measures of fledging success, recruitment and adult survival are needed to assess whether hosts incur a cost of brooding extra young. There is some evidence that gives an insight into potential costs and benefits of brooding extra non-related young. It has been shown that larger broods (crèches) suffer less gull predation in Common Eiders (Munro and Bedard 1977a). Similarly, although Lank et al. (1990) showed in Lesser Snow Geese that hosts do have the hatchability of their eggs reduced, no adverse effects to host and parasitic goslings could be detected after hatch. This suggests that there may be little or no cost in Common Eiders to accepting parasitic eggs. A possible reason why costs have been shown in other species, but not Eiders, is that Eiders are only incubating one, two or rarely three parasitic eggs. Parasitized clutches of Wood Ducks on average had almost nine extra eggs than the normal clutches (11.4 vs. 20.2; Clawson et al. 1979). It is no surprise that hatchability is reduced in the supra-normal parasitized clutches in this species. Similarly, in Redheads (Aythya americana, Weller 1959) a decrease in nesting success only occurred in host nests which received at least 4-6 parasitic eggs.

Intraspecific nest parasitism in the Hudson Bay race of the Common Eider appears to be a viable reproductive strategy. Although the number of parasitized nests is high $(30.0 \%-42.4 \%)$ there appears to be no costs to host females, probably because of the low number of parasitic eggs laid in each nest. Parasitic eggs hatch as well as host eggs because they are laid well before the host begins to incubate. Few parasitic eggs are laid at the end of the laying season suggesting that parasites are not young birds or birds in poor condition. The mechanisms of parasitism seem to 
involve parasitic females cuing in on areas o $\rightarrow$ EMLen, S. T., AND P. H. Wrege. 1986. Forced cophigh activity of nesting females and they lay their eggs in undefended nests containing one or two eggs. Other behaviors involving nest takeoverand adoption of abandoned eggs also appear to occur. Parasitism is a well refined behavior in this species and may be a viable means of ob taining reproductive output.

\section{ACKNOWLEDGMENTS}

We would like to thank M. Collins, James E. E. Kushny, R. Mulder, R. Holt, H. MacKay and B. Ganter for assistance in the collection of the data. D. B. Lank and T. D. Williams provided very helpful statistical advice and reviews to earlier manuscripts. G. J. Robertson and M. D. Watson were supported while at La Pérouse Bay by the Natural Sciences and Engineering Research Councils of Canada (NSERC) and the Department of Indian and Northern Affairs (DNIR). Queen's Uni versity Tundra Biology Station is supported by NSERC, DNIR, the Canadian Wildlife Service, the Wildlif Management Institute, the Manitoba Department of Renewable Resources, the Central and Mississippi Flyway Councils and Queen's University.

\section{LITERATURE CITED}

АмAт, J. A. 1987. Is nest parasitism among ducks advantageous to the host? Am. Nat. 130:454-457.

ANDERSSON, M. 1984. Brood parasitism within species, p. 195-228. In C. J. Barnard [ed.], Producers and scroungers: strategies of exploitation and parasitism. Croom Helm, London.

ANDERSSON, M., AND M.O.G. ERIKSSON. 1982. Nest parasitism in Goldeneyes Buchephala clangula: some evolutionary aspects. Am. Nat. 120:1-16.

Brockmann, H. J., A. Grafen, and R. Dawkins. 1979. Evolutionary stable strategy in a digger wasp. J. Theoret. Biol. 77:473-496.

Brown, C. F. 1984. Laying eggs in a neighbor's nest: benefit and cost of colonial nesting in swallows. Science 224:518-519.

CADE, W. 1980. Alternative male reproductive behaviors. Fla. Entomol. 63:30-45.

Clawson, R. L., G. W. Hartman, and L. H. Fred RICKSON. 1979. Dump nesting in a Missourı Wood Duck population. J. Wildl. Manage. 43:347355.

DAwkIns, R. 1980. Good strategy or evolutionary stable strategy?, p. 331-367. In G. W. Barlow and J. Silverberg [eds.], Beyond nature/nurture? Westview, Boulder, $\mathrm{CO}$.

EADIE, J.McA. 1989. Alternative reproductive tactics in a precocial bird. The ecology and evolution of brood parasitism in goldeneyes. Ph.D.thesis. Univ. of British Columbia, Vancouver, BC, Canada.

EAdIE, J.MCA., AND H. G. LuMSDEN. 1985. Is nest parasitism always deleterious to Goldeneyes? Am. Nat. 126:859-866.

$\rightarrow$ EAdie, J.McA., F. P. Kehoe, ANd T. D. Nudds. 1988. Pre-hatch and post-hatch brood amalgamation is North American Anatidae: a review of hypotheses. Can. J. Zool. 66:1709-1721. ulations and intra-specific nest parasitism: two costs of social living in the White-fronted Bee-eater. Ethology 71:2-29.

ERsKine, A. J. 1990. Joint laying in Bucephala ducks"parasitism" or nest-site competition. Ornis Scand. 21:52-56.

Evans, P.G.H. 1988. Intraspecific nest parasitism in the European Starling Sturnus vulgaris. Anim. Behav. 36:1282-1294.

Frederick, P. C., AND M. A. Shields. 1986. Corrections for the underestimation of brood parasitism frequency derived from daily nest inspections. J. Field Ornithol. 57:224-226.

Girard, G. L. 1939. Notes on the life history of the shoveler. Trans. North Am. Wildl. Conf. 4:364 371.

Giroux, J.-F. 1981. Interspecific nest parasitism by Redheads on islands on southeastern Alberta. Can. J. Zool. 69:2053-2057.

Hamilton, W. D. 1971. Geometry for the selfish herd. J. Theoret. Biol. 31:295-311.

Heusmann, H. W., R. Bellville, and R. G. BurRell. 1980. Further observations on dump nesting by Wood Ducks. J. Wildl. Manage. 44:908-915.

Hines, J. E., AND G. J. Mitchell. 1984. Parasitic laying in nests of gadwalls. Can. J. Zool. 62:627630.

LACK, D. 1954. The natural regulation of animal numbers. Clarendon Press, Oxford, England.

Lank, D. B., P. Mineau, R. F. Rockwell, and F. COOKE. 1989. Intraspecific nest parasitism and extra-pair copulation in lesser snow geese. Anim. Behav. 37:74-89.

LANK, D. B., R. F. Rockwell, AND F. CoOKe. 1990. Frequency-dependent fitness consequences of intraspecific nest parasitism in Snow Geese. Evolution 44:1436-1453.

LOKEMOEN, J. T. 1991. Brood parasitism among waterfowl nesting on islands and peninsulas in North Dakota. Condor 93:340-345.

MACWHIRTER, R. B. 1989. On the rarity of intraspecific brood parasitism. Condor 91:485-492.

Maynard Smith, J. 1982. Evolution and the theory of games. Cambridge Univ. Press, Cambridge, England.

MiLne, H. 1974. Breeding numbers and reproductive rates of eiders at the Sands of Forvie National Nature Reserve, Scotland. Ibis 116:135-154.

Moller, A. P. 1987. Intraspecific nest parasitism and anti-parasite behavior in swallows, Hirundo rustica. Anim. Behav. 35:247-254.

MunRo, J., AND J. BeDARD. 1977a. Gull predation and crèching behavior in the common eider. $J$. Anim. Ecol. 46:799-810.

MunRo, J., AND J. BedARd. 1977b. Crèche formation in the common eider. Auk 94:759-771.

RoBERTSON, D. J. 1929. Notes on the breeding-habits of the eider in the Orkneys. Br. Birds 23:26-30.

RoHWER, F. C. 1984. Patterns of egg-laying in prairie ducks. Auk 101:603-605.

ROHWER, F. C. 1985. The adaptive significance of clutch size in prairie ducks. Auk 102:354-361.

Rohwer, F. C., AND S. Freeman. 1989. The distri- 
bution of conspecific nest-parasitism in birds. Can. J. Zool. 67:239-253.

SAS InSTITUTE. 1985. SAS version, 5th ed. SAS Institute Inc., Cary, NC.

SchmutZ, J. K., R. J. Robertson, AND F. COOKe. 1983. Colonial nesting of the Hudson Bay eider duck. Can. J. Zool. 61:2424-2433.

$\rightarrow$ Semel, B., AND P. W. Sherman. 1986. Dynamics of nest parasitism in Wood Ducks. Auk 103:813816.

Semel, B., P. W. Sherman, ANd S. M. Byers. 1988. Effects of brood parasitism and nest-box place ment on Wood Duck breeding ecology. Condor 90:920-930.

Sorenson, M. D. In press. Parasitic egg laying in canvasbacks: frequency, success and individual behavior. Auk.

SPURR, E. B., AND H. MilnE. 1976. Factors effecting laying date in the Common Eider. Wildfowl 27: 107-109.
SwENNEN, C. 1989. Gull predation on eider Somateria mollissima ducklings: destruction or elimination of the unfit? Ardea 77:21-45.

Weller, M. W. 1959. Parasitic egg laying in the Redhead (Aythya americana) and other North American Anatidae. Ecol. Monogr. 29:333-365.

$\rightarrow$ Wells, K. D. 1977. The social behavior of anuran amphibians. Anim. Behav. 25:666-693.

Westneat, D. F., P. W. Sherman, AND M. L. Morton. 1990. The ecology of evolution of extra-pair copulation in birds. Current Orn. 7:331-369.

Yom-Tov, Y. 1980. Intraspecific nest parasitism in birds. Biol. Rev. Cambridge Philos. Soc. 55:93108.

Young, A. D., AND R. D. TITMAN. 1988. Intraspecific nest parasitism in Red-breasted Mergansers. Can. J. Zool. 66:2454-2458. 